\title{
Effect of pumpkin seed oil on cholesterol fractions and systolic/diastolic blood pressure
}

\author{
Azmat Khalid MAJID ${ }^{1}$, Zaheer AHMED ${ }^{1 *}$ (D), Rezzan KHAN ${ }^{2}$
}

\begin{abstract}
Pumpkin seed oil (PSO) is high in unsaturated fatty acids and plant sterols, which have numerous cardiovascular benefits. The study explores the hypothesis by investigating effects of consumption of $1000 \mathrm{mg}$ of PSO on total cholesterol (TC), low density lipoprotein (LDL), high density lipoprotein (HDL), systolic (SBP) and diastolic (DBP) blood pressure ((BP). PSO has high oxidative stability and contains favorable essential fatty acids profile along with sterols and tocopherols. One hundred and twenty-seven participants 39 to 63 years old, with varying degree of one or multiple medical conditions including dyslipidemia, hypertension, diabetes and obesity were randomly selected and assigned among case and control groups. Both groups were biochemically, anthropometrically and clinically assessed pre and post intervention. Group 1 (cases) ( $n=63)$ was administered $1000 \mathrm{mg}$ of PSO along with recommendations for healthy diet and lifestyle whereas Group 2 (controls) ( $\mathrm{n}=64$ ), was only provided with dietary and lifestyle changes. Analysis of cases baseline and endpoint data revealed advantageous effect of intervention. Cases data showed a significant reduction in endpoint LDL and DBP values along with a likewise significant increase in HDL cholesterol. Experiment results revealed PSO possessed hypolipidemic and anti-hypertensive activity as it lowered DBP and LDL and increased HDL levels.
\end{abstract}

Keywords: pumpkin seed oil; low density lipoproteins; hypertension; blood pressure.

Practical Application: $1000 \mathrm{mg}$ of cold extracted Pumpkin seed oil can be used as adjuvant nutrition for balancing lipids and alleviating early onset of hypertension.

\section{Introduction}

In populations all across the globe hypertension and dyslipidemia is a common occurrence and associated with negative long term prognosis. Unhealthy lifestyle habits and inadequate consumption of poly and monounsaturated fats and sterols are suggested to be partially responsible. PSO has been valued from historical times for its health potential and is packed with heart healthy essential fatty acids, plant sterols and tocopherols. In absence of data on local cultivars, the study looked at PSO's compositional analysis from all over the world. For all varieties, $100 \mathrm{~g}$ of PSO contained at least $419 \mathrm{mg}$ of heart friendly tocopherols including $128 \mathrm{mg}$ of $\alpha$ Tocopherol, $114 \mathrm{mg}$ of $\gamma$-Tocopherol and $177 \mathrm{mg}$ of $\delta$-Tocopherol (Butinar et al., 2011; Rabrenović et al., 2014). Total unsaturated fatty acid (TUFA) content ranged from $73.1 \%$ to $80.5 \%$, for different cultivars from around the globe and contained $(<1 \%)$ of linolenic acid (Stevenson et al., 2007). All varieties were valuable sources of fatty acids with more than $40 \%$ oleic acid, $33.1 \%$ linoleic acid and $14.7 \%$ palmitic acid. The studies also reported more than $27 \mathrm{mg} / 100 \mathrm{~g}$ of phytosterols content (Richter et al., 2013; Nakić et al., 2006) of which $39 \%$ was in form of lipid lowering $\beta$ Sitosterol (Rezig et al., 2012). PSO's polyunsaturated fatty acids content was found to be stable, as oxidation was inhibited by presence of accompanying endogenous antioxidants (Fruhwirth et al., 2003; Miller et al., 2011; Ryan et al., 2007).

Pumpkin seeds and its oil are attributed with anti-diabetic, antihypertensive and anti-hypercholesterolemia properties (Cedó,
Farràs, \& Lee-Rueckert) and evidence from epidemiological studies have prompted a number of investigations to test its pharmacological potential (Caili et al., 2006). PSO consumption mitigate several CVD risk factors and lower triacylglycerol concentrations (Kris-Etherton et al., 1999). PSO's phytosterol content has also been of interest because of its reported benefits on post-menopausal bone density (Richter et al., 2013). Noticeable increase in HDL concentration have been observed in postmenopausal women when diets were supplemented with PSO (Gossell-Williams et al., 2011). Phytosterol supplementation can positively benefit maternal hypercholesterolemia (Dumolt et al., 2018). One possible mechanism for phytosterols effect on cholesterol fractions can be attributed to inhibiting cholesterol absorption in the small intestine by modulating transformation of bile acids into secondary bile acids, and reducing hydrophobic/hydrophilic ratio (Cedó et al., 2019; Nissinen et al., 2002). Dietary PSO can improve intestinal concentrations of stanols, which reduces cholesterol's micellar solubility and leads to a reduced absorption of cholesterol (Demonty et al., 2009; Phillips et al., 2005).

It has been reported that plant sterols including the ones contained in PSO can act as endocrine and metabolic facilitators by benefiting insulin sensitivity, obesity and menopausal women or low estrogen conditions (Usui, 2006), while alpha tocopherols content can positively effect initial events in atherosclerosis (Miranda et al., 2018). Pumpkin seeds are also a source of phenols, which have shown potential in cancer prevention (Liu, 2004). 
Additionally, PSO has been reported to benefit hyperglycemia besides hypertension (Montesano et al., 2018). Biochemically active phytoestrogens from pumpkin seeds physically and functionally behave as estrogens and have exhibited potential benefits through various mechanisms (Demonty et al., 2009). A sectional study of 301 postmenopausal women aged 60-75 years, reported protective effect of phytoestrogens on hypertension - even at low levels of dietary intake (Kreijkamp-Kaspers et al., 2004). Multiple investigations have indicated its hypolipidemic potential along with anti-glycemic properties (Montesano et al., 2018; Patel, 2013). Its anti-androgenic properties play a positive supportive role in urinary disorders, prostate gland and urinary bladder diseases (Đorđević et al., 2016) besides preventing fatty liver (Al-Okbi et al., 2017).

LDL and HDL are among five main types of lipoproteins, with similar density and size. Both lipoprotein's functional properties have a direct impact on CVDs. PSO composition favorably affects HDL and LDL balance, therefore it was considered worthy of exploration in local context. HDL plays a critical role in movement of cholesterol from peripheral tissues to plasma and liver, where cholesterol is synthesized into bile before excretion (Randolph \& Miller, 2014). Data of twenty six trials showed that all-cause coronary heart disease mortality reduced by $10 \%$ with a $1 \mathrm{mmol} / \mathrm{L}$ LDL reduction (Mancia et al., 2013; Trialists, 2010). Similarly, HDL is not only unquestionably cardio protective because of its function in reverse cholesterol transport but also has beneficial effects on endothelial cells and antioxidant activity (Assmann \& Gotto, 2004). Even though with a heightened focus on HDL, increasing HDL is not a foremost conventional therapy target. It has been proposed for decades that treatment of hypercholesterolemia must address low HDL levels while reducing total and LDL cholesterol levels. PSO's pharmacological properties make it a cost effective and safe option for a supportive treatment, as it can beneficially influence HDL and LDL fractions, for long term prevention of CVD (Ras et al., 2014).

In animal models, PSO's combinational administration with arginine, alleviated oxidative injury and restored fatty liver (Al-Okbi et al., 2014) and induced increases in HDL with a 47\% and $78 \%$ reduction in TC and LDL respectively (Abuelgassim \& Al-Showayman, 2012; Alsina et al., 2016). PSO's stanol content lowered LDL without reduction in vitamin A (Gylling et al., 2010 ) and showed antihypertensive potential induced by nitric oxide deficiency (El-Mosallamy et al., 2012).

Prospective observational data of 1435 patients showed that LDL lowering strategies also reduced levels of oxidized LDL and adverse coronary events (Schettler et al., 2017) and atherosclerosis leading to CVD (Rafieian-Kopaei et al., 2014). Whereas, an increase in HDL delivers significant CVD prevention (Barter, 2011). PSO has a balancing effect, not only on lipids, blood sugar, liver, prostate and bladder (Montesano et al., 2018; Patel, 2013) but it also augments arterial health and can reduce hypertension in postmenopausal women (Wong et al., 2019). This makes PSO a suitable supportive treatment option and worthy of further exploration. In continuation to the described work, this study further investigates influence of PSO supplementation, by evaluating its effect on TC, LDL, HDL SBP and DBP.

\section{Materials and methods}

The research was based on an observational experiment, for determining effects of a 90-day intervention of $1000 \mathrm{mg}$ of cold extracted pumpkin seed oil on TC, LDL, HDL, SBP and DBP. Participants were given American Heart Association's recommended standard heart healthy diet and lifestyle modifications guidelines whereas, group 1 (cases) diet was supplemented with commercially available gel capsule of $1000 \mathrm{mg}$ of cold extracted PSO. Its composition of heart healthy essential fatty acids (monounsaturated as oleic acid (41.4\%) and polyunsaturated fats as linoleic acid (37.0\%),) and sterols including stigmastatrienol, tigmastadienol, and spinasterol have been of great interest lately because of their therapeutic value. Furthermore, it is cost effective, widely available and carries a myth of a "healing oil" in local folklore.

Biochemical investigation, clinical evaluation, anthropometric assessment and lifestyle analysis were conducted at baseline and endpoint. Participants were clinically reexamined at mid-point period of 45 days and dietary and lifestyle guidelines was recorded. The study participation was voluntary and conducted at NWPC clinic in Lahore, Pakistan. The inclusion criteria consisted of a formal diagnosis of one or more of the following conditions; metabolic syndrome or diabetes or CVD. Two hundred and fifty-two randomized individuals were invited to join. Ninety-eight were excluded due to delayed response. Invitees were screened and finalized from a clinical setting. Initially $(\mathrm{n}=252)$ responded and wished to be part of the investigation. At baseline, $(n=149)$ subjects enrolled for the study. Participants were randomly assigned to case (group 1) and control (group 2) group. After taking into account pre baseline exclusions, group 1 contained $(\mathrm{n}=74)$ whereas group 2 consisted of $(\mathrm{n}=75)$ participants (Figure 1$)$.

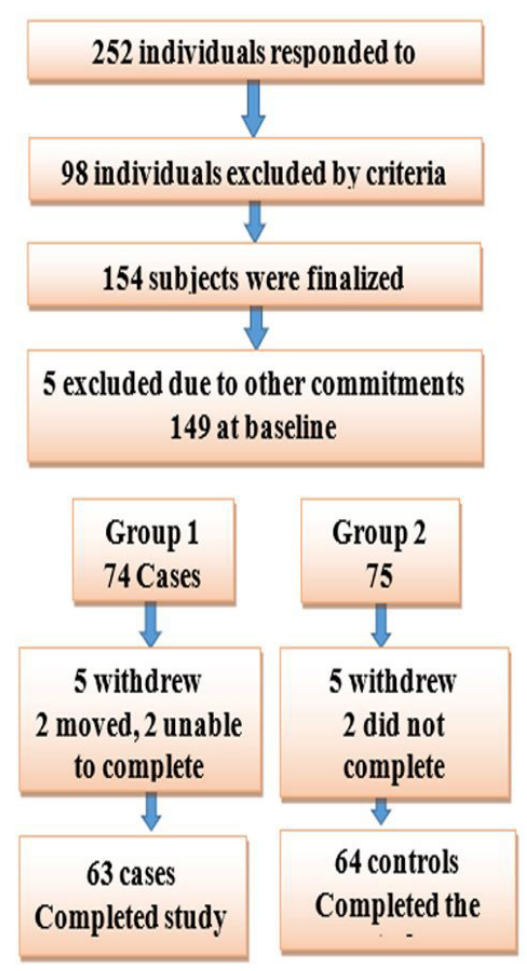

Figure 1. Subject selection flow diagram and trial profile. 
At endpoint, group 1 Cases comprised of $(n=63)$ whereas group 2 contained $(n=64)$ participants, who completed study protocols. Group 1 comprised of 36 males and 29 females and group 2 comprised of 33 males and 31 females. Participant ages, who completed the study ranged between 39 to 63 years. Lipid profiles along with systolic and diastolic values were documented along with anthropometric and clinical assessments before, during and after intervention. The demographic profile and educational background and socioeconomic status of study subjects is depicted in Table 1.

\subsection{Ethical approval}

The study was duly approved by the NWPC Clinic's ethical committee. The study was conducted in accordance with the guidelines set forth by the Declaration of Helsinki. Participants were fully informed about objectives of the study and a written consent was obtained, before enrollment.

\subsection{Lifestyle, anthropometric and biochemical assessment}

Lifestyle associations with disease prevention have been around for ages which stand validated by many modern-day studies. During baseline clinical evaluation, dietary and lifestyle investigation was conducted through a semi-structured interview

Table 1. Identifying characteristics of Subjects.

\begin{tabular}{|c|c|c|}
\hline Characteristics & Cases & Control \\
\hline $\begin{array}{l}\text { Total Number (Group } 1 \mathrm{~N}=63 \text { ) } \\
\text { (Group } 2 \mathrm{~N}=64 \text { ) }\end{array}$ & $100(63)$ & $100(64)$ \\
\hline Male & 57 & 52 \\
\hline Female & 43 & 48 \\
\hline \multicolumn{3}{|l|}{ Age Groups } \\
\hline $39-50$ & 43 & 45 \\
\hline $51-65$ & 57 & 55 \\
\hline \multicolumn{3}{|l|}{ Economic Distribution } \\
\hline High Income Group & 13 & 15 \\
\hline Middle Income Group & 57 & 59 \\
\hline Low Income Group & 30 & 26 \\
\hline \multicolumn{3}{|l|}{ Educational Background } \\
\hline Limited Or No Education & 12 & 14 \\
\hline 8 To 12 Grades & 19 & 23 \\
\hline 12 Grades & 18 & 20 \\
\hline Bachelors & 43 & 40 \\
\hline Masters Or More & 8 & 3 \\
\hline \multicolumn{3}{|l|}{ Life Style } \\
\hline Sedentary & 55 & 62 \\
\hline Moderately Active & 29 & 25 \\
\hline Active & 16 & 13 \\
\hline \multicolumn{3}{|l|}{ Formal Diagnosis } \\
\hline Dyslipidemia & 74 & 66 \\
\hline Hypertension & 77 & 71 \\
\hline Cerebrovascular Disease & 2 & - \\
\hline Pulmonary Embolism & 2 & - \\
\hline Cardiovascular Disease & 27 & 34 \\
\hline Diabetes Type I \& II & 23 & 28 \\
\hline Metabolic Syndrome/Obesity & 29 & 27 \\
\hline
\end{tabular}

for categorizing participants as sedentary, moderate or active. Sedentary categorization represented mostly passive activities, such as TV watching, working on computer, reading, driving and or staying at home etc. Whereas, "moderate" represented some physical activities, such as a 20-minute walk (3 times a week) and some weekly sports activity. The "active" category represented at least 20 minute of regular physical activity ( 5 days in a week or more) including cardiovascular exercises, or walks, or yoga or gym or playing some sports.

Anthropometric evaluation comprised of dimensional descriptors including height, weight, waist, neck size and hip circumference. The measurements were conducted with help of an anthropometric measuring tape with a range of 60 inches, height stand and Beurer GS58 weighing machine. Body mass index (BMI) was calculated by using $\mathrm{kg} / \mathrm{m}^{2}$ ratio. BP was measured thrice, and average value was recorded by nursing staff, utilizing a mechanical aneroid sphygmomanometer.

Guidelines set forth by the American Heart Association (Miller et al., 2011) and the International College of Cardiology (Hilton Chaves et al., 2016) were followed. The levels of TC, HDL and LDL were determined from serum using Hitachi 704 Analyzer, serviced by Roche Diagnostics. Reference ranges of assessed parameters are presented in Table 2. Blood samples were taken at baseline and then after 90 days of intervention. Tests were done after a 12 hour fast and were measured at baseline and endpoint. Corresponding reference ranges are given in the Table 2 .

\subsection{Dietary and lifestyle guidelines}

Diet and lifestyle are key to prevention from many medical conditions and are often traditionally considered to be proven ways of improving health. Keeping the above fact in mind, all subjects including group 1 (cases) and group 2 (controls) were all furnished similar American Heart Association's heart healthy dietary guidelines. Dietary guidelines served as the common denominator between both groups and also included recommendations to reduce beverages and foods with added white refined sugars and were asked to reduce their salt intake. Furthermore, participants were asked to limit animal and saturated fat by choosing fatty fish, poultry without skin, low fat dairy and nuts. The diet emphasized daily consumption of whole grains, fresh fruits and vegetables. Subjects were required to include whole grains, legumes, fish, fresh fruits and vegies to their diet. To determine compliance levels, subjects were required to maintain a "Daily Food and Activity Diary".

Table 2. Reference Ranges for TC, LDL, HDL.

\begin{tabular}{ll}
\hline $\begin{array}{c}\text { Biochemical } \\
\text { Parameters }\end{array}$ & \multicolumn{1}{c}{ Reference Ranges } \\
\hline $\begin{array}{l}\text { HDL Cholesterol } \\
\text { LDL Cholesterol }\end{array}$ & $\begin{array}{l}\text { 100-129 Near/above optimal, 130-159 Borderline } \\
\text { high, 160-189 High, }>190 \text { Very high }(\mathrm{mg} / \mathrm{dL})\end{array}$ \\
Total Cholesterol & $\begin{array}{l}<200 \text { Desirable, 200-239 Borderline high }>240 \text { High } \\
\text { (in mg/dL) }\end{array}$ \\
\hline TC: Total cholesterol; LDL: Low density lipoprotein; HDL: High density lipoprotein.
\end{tabular}




\section{Results of investigation}

Baseline and endpoint data of cases and controls was independently analyzed, and cross compared. At baseline biomarker numbers were comparable for both groups and efforts were made to limit confounding variables, which may influence dependent variables. Table 3 comprises of case group's baseline and endpoint mean values along with independent sample t-test at $95 \%$ confidence interval for comparing the difference between pre and post intervention data. The $\mathrm{t}$-test, mean and $\mathrm{p}$ values were found to be statistically significant for LDL ( $p=.005)$, HDL $(p=.000)$ and DBP $(p=.001)$ variables respectively. Results were not indicative of any significant effect on TC $(p=.230)$ and SBP $(p=.154)$. Case group's findings are in accordance with long held view that PSO consumption can lead to improvements in $\mathrm{BP}$ and lipids.

The results for TC as dependent variable indicated a statistically insignificant difference in pre and post TC numbers. A slightly higher mean value was obtained in pre group subjects $(\mathrm{M}=185.254 \pm 19.825)$ than post group subjects $(\mathrm{M}=181.190 \pm 17.970)$ with a $p$-value of 0.230 . Statistical analysis of baseline and endpoint LDL showed a relatively significant effect of intervention as indicated by $p$-value score of 0.005 . This was also corroborated by a higher baseline mean value for LDL numbers $(\mathrm{M}=145.667 \pm 35.071)$ when compared with endpoint LDL mean value of $(M=130.048 \pm 25.078)$. Analysis of pre and post intervention HDL numbers showed that there was statistically significant difference evident by $p$-value score of 0.000 . A lower mean value for HDL was seen in baseline numbers $(M=38.127 \pm 6.356)$ than endpoint mean HDL value of $(M=42.610 \pm 6.780)$. The effect of intervention on SBP was peripheral. This was also evident from mean value for baseline SBP $(\mathrm{M}=126.571 \pm 4.563)$ when compared with endpoint mean value of $(\mathrm{M}=125.270 \pm 5.582)$. Analysis of pre and post intervention for DBP showed a statistically significant $p$-value $=0.001$ which was further corroborated by mean DBP value at baseline $(\mathrm{M}=84.381 \pm 4.097)$ and endpoint $(\mathrm{M}=81.048 \pm 6.449)$.

Scrutiny of case subjects' pre and post intervention data (Figure 2) and maximum and minimum values (Figures 3A, 3B) for TC, LDL, HDL, SBP and DBP at baseline and endpoint, showed a significant improvement in DBP and a positive effect on overall BP. The biggest decrease in DBP was $16.38 \mathrm{mmHg}$ and was not limited to any gender and was even manifest in participants with nominal change in diet and lifestyle. A substantial decrease in LDL levels was especially seen among those subjects whose LDL scores were most out of range. The biggest reduction in LDL levels stood at $59.22 \mathrm{mg} / \mathrm{dL}$ while maximum improvement recorded in HDL levels amounted to $15.12 \mathrm{mg} / \mathrm{dL}$. The increase in atheroprotective HDL is always highly desirable as it provides highly beneficial vasodilation, cytoprotecting and antithrombotic effects. This study's results supported earlier findings that showed PSO has an anti-hypertensive effect and lowers LDL levels (Ellegård et al., 2007).

During baseline clinical examination, 7 menopausal women participants (cases $=3$, controls $=4$ ) reported experiencing severe symptoms. At endpoint it was revealed that their intensity and frequency of recurring flushing episodes reduced substantially during the intervention. When asked about the exact nature of relief felt - the responses included reduction in hot flashes, better mood, sleep and libido. How much of the said improvement can be linked to dietary and lifestyle changes or to phytoestrogens content of PSO needs to be investigated as PSO has earlier demonstrated menopausal relief (Lyttle et al., 2008). It is well known that many similar plant phytoestrogens have been found to have potential in treatment of menopausal symptoms and is supported by previous findings from 29 randomized controlled clinical trials (Kronenberg \& Fugh-Berman, 2002). Researchers attribute higher intake of phytoestrogens in Far Eastern women with reduced incidence of menopausal symptoms, cardiovascular disease, cancer and osteoporosis in comparison to western women (Torella et al., 2013).

Furthermore, twenty cases experienced $a \geq 10 \%$ or more reduction in their LDL levels whereas, seventeen case subjects recorded $\mathrm{a} \geq 10 \%$ increase in HDL along with nineteen subjects who experienced a $\geq 5 \%$ decrease in SBP as shown in Figures $3 \mathrm{~A}$ and $3 \mathrm{~B}$.

Table 4 comprises of control groups pre and post intervention data along with independent sample t-test at $95 \%$ confidence interval for comparative analysis. The $t$-test, mean and $p$ values for control group were not found to be statistically significant for TC $(p=0.329), \mathrm{LDL}(p=0.131), \mathrm{HDL}(p=0.087), \mathrm{SBP}(p=0.086)$ and DBP ( $p=0.467)$ variables respectively. Control groups findings are in accordance with long held view that low cholesterol diet

Table 3. Cases (Group 1): Independent sample t-test of baseline and endpoint values.

\begin{tabular}{|c|c|c|c|c|c|c|c|}
\hline & Cases Group 1 & ${ }^{*} N$ & Mean & ${ }^{*} S D$ & ${ }^{*} t \prime$ & ${ }^{*} d f$ & ${ }^{*} p$ \\
\hline \multirow[t]{2}{*}{${ }^{*} \mathrm{TC}(\mathrm{mg} / \mathrm{dL})$} & Baseline & 63 & 185.254 & 19.8250 & 1.205 & 124 & 0.230 \\
\hline & Endpoint & 63 & 181.190 & 17.9703 & & & \\
\hline \multirow[t]{2}{*}{${ }^{\star} \mathrm{LDL}(\mathrm{mg} / \mathrm{dL})$} & Baseline & 63 & 145.667 & 35.0718 & 2.875 & 124 & 0.005 \\
\hline & Endpoint & 63 & 130.048 & 25.0789 & & & \\
\hline \multirow[t]{2}{*}{${ }^{*} \mathrm{HDL}(\mathrm{mg} / \mathrm{dL})$} & Baseline & 63 & 38.127 & 6.3563 & -3.828 & 124 & 0.000 \\
\hline & Endpoint & 63 & 42.610 & 6.7804 & & & \\
\hline \multirow[t]{2}{*}{${ }^{\star} \mathrm{SBP}(\mathrm{mmHg})$} & Baseline & 63 & 126.571 & 4.5639 & 1.433 & 124 & 0.154 \\
\hline & Endpoint & 63 & 125.270 & 5.5828 & & & \\
\hline \multirow[t]{2}{*}{${ }^{*} \mathrm{DBP}(\mathrm{mmHg})$} & Baseline & 63 & 84.381 & 4.0973 & 3.463 & 124 & 0.001 \\
\hline & Endpoint & 63 & 81.048 & 6.4494 & & & \\
\hline
\end{tabular}

N: Number; TC: Total cholesterol; LDL: Low density lipoprotein; HDL: High density lipoprotein; SBP: systolic blood pressure; DBP: diastolic blood pressure; SD: standard deviation; $d f$ : degree of freedom; ' $t$ ': student $\mathrm{T}$ test $\left({ }^{*} \mathrm{p}<0.05\right)$. 


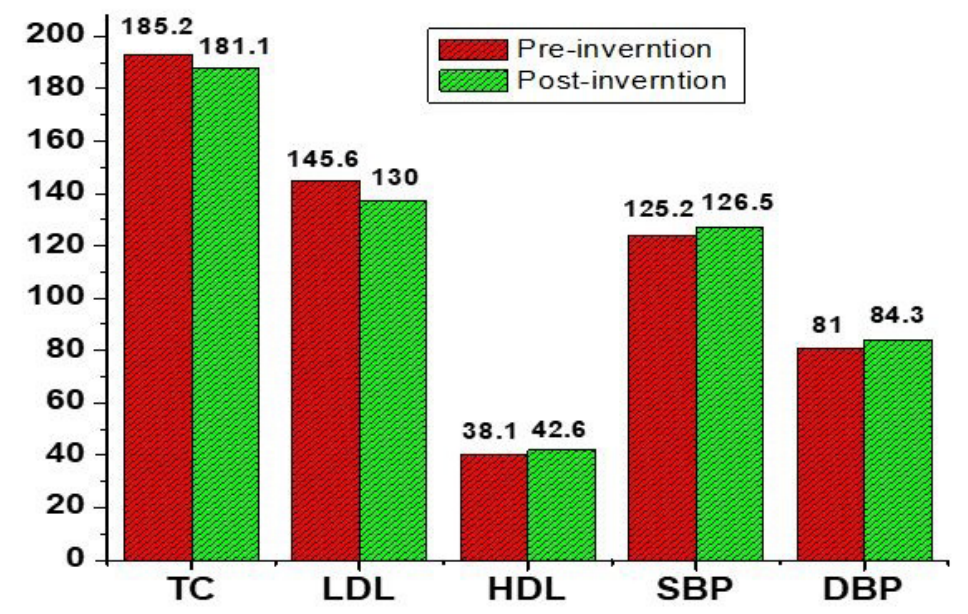

$\mathbf{A}$

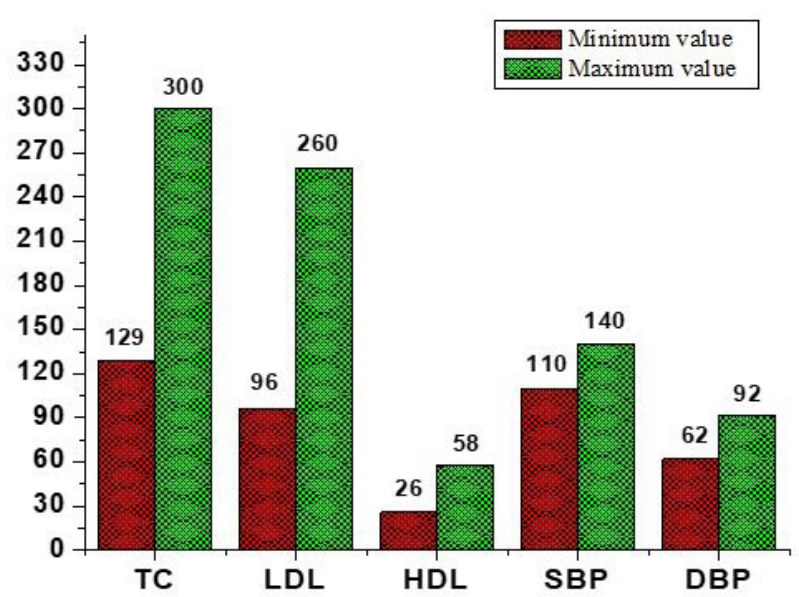

B

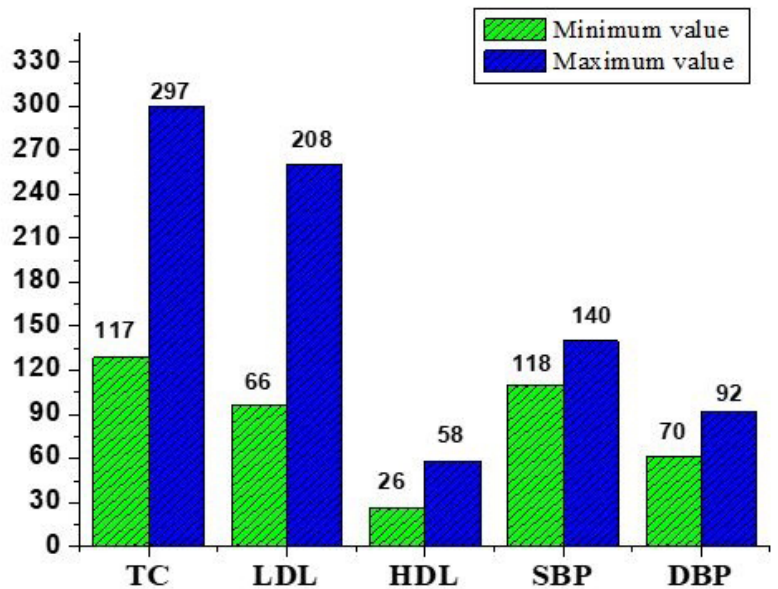

C

Figure 2. (A) Pre and post intervention comparison of mean values recorded for Total Cholesterol (TC), Low Density Lipoprotein (LDL), High Density Lipoprotein (HDL), Systolic (SBP) and Diastolic Blood Pressure (DBP) of Group 1 (Cases); (B) Pre-Intervention Group 1 (cases) maximum and minimum values recorded for Total Cholesterol (TC), Low Density Lipoprotein (LDL), High Density Lipoprotein (HDL), Systolic (SBP) and Diastolic Blood Pressure (DBP); (C) Post-intervention Group 1 (cases) maximum and minimum values recorded for Total Cholesterol (TC), Low Density Lipoprotein (LDL), High Density Lipoprotein (HDL), Systolic (SBP) and Diastolic Blood Pressure (DBP).

leads to enhanced endogenous production of cholesterol. Control group subjects carried a similar formal diagnosis as of case group subjects. The post intervention data of control group subjects did not show a mentionable beneficial effect.

To test the hypothesis and ascertain the interventional effect of $1000 \mathrm{mg}$ of PSO, cases and control data was compared. Group 1 cases (PSO + dietary and lifestyle guidelines) showed a reduction of $2.193 \%$ in TC levels; whereas, group 2 controls (dietary and lifestyle guidelines only) recorded a reduction of $2.811 \%$, indicating sound nutrition and a healthy lifestyle, does matter. The effect of PSO reflected in Case group's LDL levels, which decreased by $10.722 \%$, whereas Control group's LDL numbers, who were only advised dietary and lifestyle changes, also showed a decrease of $5.628 \%$, revealing an impressive impact of a healthy diet and exercise. HDL for cases and controls showed an improvement of $11.175 \%$ and $4.971 \%$ respectively. SBP showed marginal effect and only reduced by cases $(1.027 \%)$ and controls (1.318\%). Results revealed a $3.881 \%$ reduction in DBP for cases group and an insignificant reduction of $0.758 \%$ for control group.

Analysis showed that $53.1 \%$ of cases and $51.4 \%$ of controls followed a majority ( $75 \%$ or more) of dietary guidelines whereas $38.2 \%$ of cases and $35.7 \%$ of controls followed ( $75 \%$ or more) of recommended lifestyle changes. Both groups' adherence 


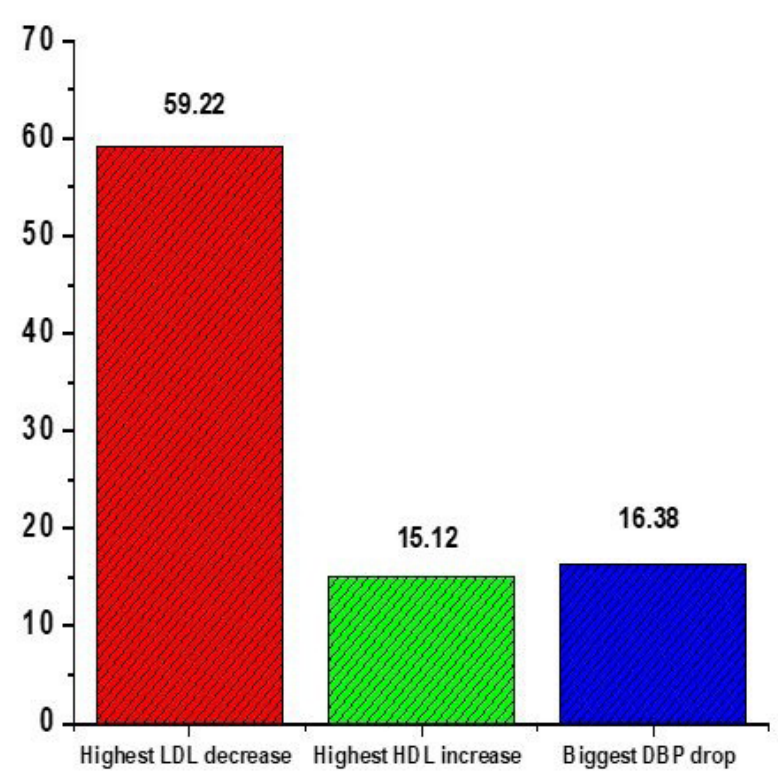

A

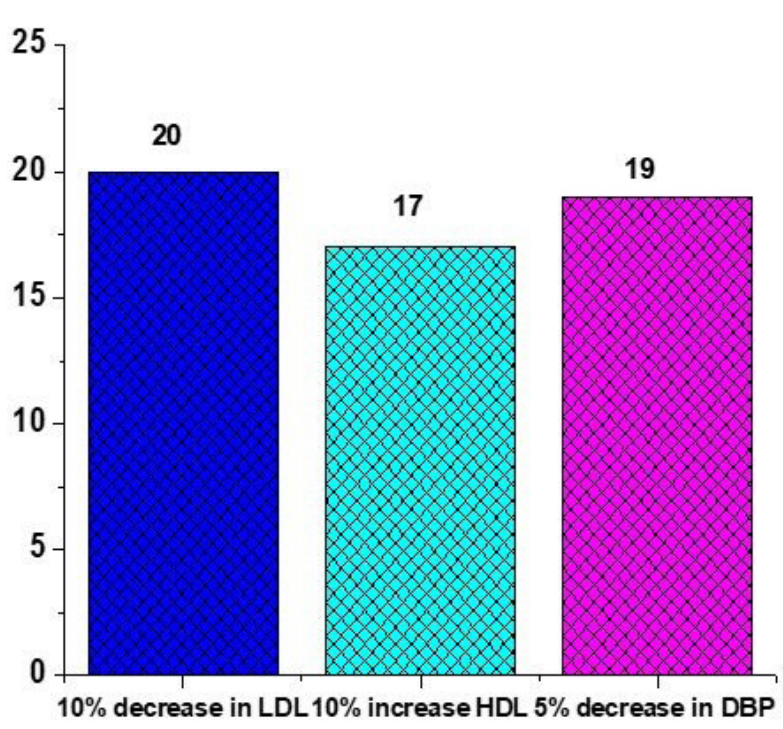

B

Figure 3. (A) (Group 1, $\mathrm{n}=63$ ) Best single decrease in low density lipoprotein (LDL) and highest single increase in high density lipoprotein (HDL) levels and the most decrease in Diastolic Blood Pressure (DBP; (B) Group 1, $\mathrm{n}=63$ ) - Shows number of subjects with $>10 \%$ decrease in LDL and number of subjects with $>10 \%$ increase high density lipoprotein (HDL) and number of subjects $>5 \%$ decrease in diastolic blood pressure (DBP). (TC in $\mathrm{mg} / \mathrm{dL}, \mathrm{LDL}$ in $\mathrm{mg} / \mathrm{dL}, \mathrm{HDL}$ in $\mathrm{mg} / \mathrm{dL}$ and $\mathrm{DBP}$ in $\mathrm{mmHg}$ ).

Table 4. Controls: Independent sample t-test at baseline and endpoint.

\begin{tabular}{|c|c|c|c|c|c|c|c|}
\hline & Control Group & ${ }^{*} N$ & Mean & ${ }^{*} S D$ & ${ }^{*} t^{\prime}$ & ${ }^{\star} d f$ & ${ }^{*} p$ \\
\hline \multirow[t]{2}{*}{${ }^{*} \mathrm{TC}(\mathrm{mg} / \mathrm{dL})$} & Baseline & 64 & 193.16 & 30.639 & 0.980 & 126 & 0.329 \\
\hline & Endpoint & 64 & 187.72 & 32.139 & & & \\
\hline \multirow[t]{2}{*}{${ }^{\star} \mathrm{LDL}(\mathrm{mg} / \mathrm{dL})$} & Baseline & 64 & 145.14 & 35.046 & 1.521 & 126 & 0.131 \\
\hline & Endpoint & 64 & 136.97 & 24.887 & & & \\
\hline \multirow[t]{2}{*}{${ }^{\star} \mathrm{HDL}(\mathrm{mg} / \mathrm{dL})$} & Baseline & 64 & 40.22 & 6.273 & -1.724 & 126 & 0.087 \\
\hline & Endpoint & 64 & 42.22 & 6.842 & & & \\
\hline \multirow[t]{2}{*}{${ }^{*} \mathrm{SBP}(\mathrm{mmHg})$} & Baseline & 64 & 127.38 & 5.332 & 1.728 & 126 & 0.086 \\
\hline & Endpoint & 64 & 125.70 & 5.611 & & & \\
\hline \multirow[t]{2}{*}{${ }^{*} \mathrm{DBP}(\mathrm{mmHg})$} & Baseline & 64 & 84.28 & 4.006 & 0.729 & 126 & 0.467 \\
\hline & Endpoint & 64 & 83.64 & 5.777 & & & \\
\hline
\end{tabular}

N: Number; TC: Total cholesterol; LDL: Low density lipo protein; HDL: High density lipoprotein; SBP: systolic blood pressure; DBP: diastolic blood pressure; SD: standard deviation; $d f$ : degree of freedom; ' $t$ ': student $\mathrm{T}$ test $\left({ }^{*} \mathrm{p}<0.05\right)$.

levels were found comparable and the data confirms earlier work (Mancia et al., 2013; Trialists, 2010; Assmann \& Gotto, 2004; Ras et al., 2014) which shows that PSO has a therapeutic potential in lowering LDL, DBP while increasing HDL levels.

\section{Discussion}

It can be argued that improvements in control group's HDL, LDL and SBP readings were due to multifactorial effect of diet, exercise and intervention, Whereas, insignificant improvement in TC was due to enhanced endogenous cholesterol when it was exogenously limited. Nonetheless, to ascertain influence of intervention, a comparative analysis of both groups observance levels to diet and lifestyle guidelines, was conducted and found comparable. For better CVD health LDL and HDL, provide considerable predictive significance and relative risk (Sharrett et al., 2001). Any LDL lowering protocol merits serious investigations, because of LDL's role as best differentiator of coronary artery disease (Gardner et al., 1996). Besides reducing LDL, PSO facilitated HDL synthesis and reduce arterial BP, thereby supporting overall prevention strategies. The expert panel of the American College of Cardiology and the American Heart Association Task Force, also supports LDL lowering and HDL facilitating strategies for prevention of atherosclerosis and CVD events (Bai, 2019; Barylski et al., 2014; Stone et al., 2014). Earlier, similar work has shown PSO to a worthy preventive option because of its ability to favorably benefit lipid fractions and act as an anti-hypertensive. Study results show that PSO supplementation, can be a viable 
adjuvant supportive treatment as it enables better HDL, reduces LDL and DBP - all of which are focal points of CVD management. DBP fluctuations especially, carry an adverse prognosis and PSO's salutary effect on DBP is therapeutically valuable. PSO's positive effect on highly complex HDL metabolism provides remarkable protection against progression of atherosclerosis and oxidation and endothelial dysfunction.

PSO's favorable effect on can be attributed to its constituents of highly favorable $\beta$-sitosterol (Rezig et al., 2012) and a favorable fatty acids profile, mostly found in an unsaturated state (Nakić et al., 2006). These nutritional factors have shown to positively affect lipid profile, hypertension and can prevent abnormalities associated with deficiency or availability of estrogen (Lyttle et al., 2008). Structurally sterols are 15-30 times less absorbable than cholesterol, which results in partial inhibition of intestinal cholesterol absorption (Demonty et al., 2009). PSO's immense therapeutic value is further strengthened when it is also considered safe for long term consumption for prevention of CVDs (Baumgartner et al., 2019). The benefits are not only limited just to oil from pumpkin seeds but its seeds have also been recognized with same anti-atherogenic and cytoprotective properties (Makni et al., 2008).

Food technologists have investigated structural and function aspects of pumpkin seeds (Ahmed et al., 2014) and developed snacks like enriched bread (Kampuse et al., 2015) and is being used as a food additive in numerous products including sweets, and crackers (Kaur et al., 2019). The objective is to deliver an effective phytosterol dose of 1.5 to $3 \mathrm{~g} /$ day, as it can lead to an 8 to $15 \%$ reduction in LDL-cholesterol (Kampuse et al., 2015; Kaur et al., 2019). Sterols have a wide ranging therapeutic potential as anticancer, anti-inflammation, hypoglycemic and immune modulators, and are effective with or without meals (Lestari \& Meiyanto, 2018; Adams et al., 2011; Syed et al., 2019).

The study provides many possible prospects for further lines of research. The extent of CVD prevention, offered by management of dyslipidemia and hypertension with long term PSO supplementation, needs to be investigated. Similarly, the degree of relief of menopausal symptom, needs to be fully evaluated and dosing guidelines, should be established. For undertaking long term supportive treatments, PSO's beneficial synergic effects with other compounds should be examined.

\section{Conclusions}

Results of the experiments reveal PSO to have hypolipidemic and anti-hypertensive activity. PSO's sterol content was shown to positively affect lipid profile as it is less absorbable than cholesterol, resulting in partial inhibition of intestinal cholesterol absorption and can prevent abnormalities associated with deficiency or availability of estrogen. PSO's positive effect on highly complex HDL metabolism was evident of its remarkable protection against progression of atherosclerosis, oxidation and endothelial dysfunction. This investigation concluded that PSO is beneficial for lowering DBP and LDL while enabling an increase in HDL. No toxic effects of intervention were reported or observed.

\section{Acknowledgements}

The authors are grateful to NWPC clinics for providing facilities. The authors' contributions are as follows: A.M. led and conducted the study as part of his $\mathrm{PhD}$ and wrote the manuscript. $\mathrm{R}$. K and Z. A. oversaw as supervisor and co-supervisor.

\section{References}

Abuelgassim, A. O., \& Al-Showayman, S. I. (2012). The effect of pumpkin (Cucurbita Pepo L) seeds and L-arginine supplementation on serum lipid concentrations in atherogenic rats. African Journal of Traditional, Complementary, and Alternative Medicines, 9(1), 131-137. PMid:23983330.

Adams, G. G., Imran, S., Wang, S., Mohammad, A., Kok, S., Gray, D. A., Channell, G. A., Morris, G. A., \& Harding, S. E. (2011). The hypoglycaemic effect of pumpkins as anti-diabetic and functional medicines. Food Research International, 44(4), 862-867. http://dx.doi. org/10.1016/j.foodres.2011.03.016.

Ahmed, J., Al-Foudari, M., Al-Salman, F., \& Almusallam, A. S. (2014). Effect of particle size and temperature on rheological, thermal, and structural properties of pumpkin flour dispersion. Journal of Food Engineering, 124, 43-53. http://dx.doi.org/10.1016/j. jfoodeng.2013.09.030.

Al-Okbi, S. Y., Mohamed, D. A., Hamed, T. E., \& Esmail, R. S. (2014). Rice bran oil and pumpkin seed oil alleviate oxidative injury and fatty liver in rats fed high fructose diet. Polish Journal of Food and Nutrition Sciences, 64(2), 127-133. http://dx.doi.org/10.2478/ pjfns-2013-0002.

Al-Okbi, S. Y., Mohamed, D. A., Hamed, T. E.-S., Kassem, A. A., El-Alim, S. H. A., \& Mostafa, D. M. (2017). Enhanced prevention of progression of non alcoholic fatty liver to steatohepatitis by incorporating pumpkin seed oil in nanoemulsions. Journal of Molecular Liquids, 225, 822-832. http://dx.doi.org/10.1016/j.molliq.2016.10.138.

Alsina, E., Macri, E. V., Lifshitz, F., Bozzini, C., Rodriguez, P. N., Boyer, P. M., \& Friedman, S. M. (2016). Efficacy of phytosterols and fish-oil supplemented high-oleic-sunflower oil rich diets in hypercholesterolemic growing rats. International Journal of Food Sciences and Nutrition, 67(4), 441-453. http://dx.doi.org/10.3109/ 09637486.2016.1161010. PMid:26983467.

Assmann, G., \& Gotto, A. M. Jr. (2004). HDL cholesterol and protective factors in atherosclerosis. Circulation, 109(23, Suppl. 1), III8-III14. http://dx.doi.org/10.1161/01.CIR.0000131512.50667.46. PMid:15198960.

Bai, N. (2019). Advances in the prevention of cardiovascular diseases by phytosterol. In ICMHI 2019: Proceedings of the third International Conference on Medical and Health Informatics 2019. New York: The Association for Computing Machinery. http://dx.doi. org/10.1145/3340037.3340073.

Barter, P. (2011). HDL-C: role as a risk modifier. Atherosclerosis. Supplements, 12(3), 267-270. http://dx.doi.org/10.1016/S15675688(11)70885-6. PMid:22152280.

Barylski, M., Toth, P. P., Nikolic, D., Banach, M., Rizzo, M., \& Montalto, G. (2014). Emerging therapies for raising high-density lipoprotein cholesterol (HDL-C) and augmenting HDL particle functionality. Best Practice \& Research Clinical Endocrinology \& Metabolism, 28(3), 453-461. http://dx.doi.org/10.1016/j.beem.2013.11.001. PMid:24840270.

Baumgartner, S., Ras, R. T., Trautwein, E. A., Konings, M. C., Mensink, R. P., \& Plat, J. (2019). Plasma oxyphytosterol concentrations are not associated with CVD status in Framingham Offspring Study 
participants. Journal of Lipid Research, 60(11), 1905-1911. http:// dx.doi.org/10.1194/jlr.RA119000274. PMid:31455614.

Butinar, B., Bučar-Miklavčič, M., Mariani, C., \& Raspor, P. (2011). New vitamin $\mathrm{E}$ isomers (gamma-tocomonoenol and alpha-tocomonoenol) in seeds, roasted seeds and roasted seed oil from the Slovenian pumpkin variety 'Slovenska golica'. Food Chemistry, 128(2), 505-512. http://dx.doi.org/10.1016/j.foodchem.2011.03.072. PMid:25212163.

Caili, F., Huan, S., \& Quanhong, L. (2006). A review on pharmacological activities and utilization technologies of pumpkin. Plant Foods for Human Nutrition, 61(2), 70-77. http://dx.doi.org/10.1007/s11130006-0016-6. PMid:16758316.

Cedó, L., Farràs, M., Lee-Rueckert, M., \& Escolà-Gil, J. C. (2019). Molecular insights into the mechanisms underlying the cholesterollowering effects of phytosterols. Current Medicinal Chemistry, 26(37), 6704-6723. http://dx.doi.org/10.2174/092986732666619082215470 1. PMid:31438826.

Demonty, I., Ras, R. T., Van der Knaap, H. C., Duchateau, G. S., Meijer, L., Zock, P. L., Geleijnse, J. M., \& Trautwein, E. A. (2009). Continuous dose-response relationship of the LDL-cholesterol-lowering effect of phytosterol intake. The Journal of Nutrition, 139(2), 271-284. http:// dx.doi.org/10.3945/jn.108.095125. PMid:19091798.

Đorđević, I., Milutinović, M., Kostić, M., Đorđević, B., Dimitrijević, M., Stošić, N., Ranđelović, M., Banković, S., \& Kitić, D. (2016). Phytotherapeutic approach to benign prostatic hyperplasia treatment by pumpkin seed (Cucurbita pepo L., Cucurbitaceae). Acta Medica Medianae, 55(3), 76-84. http://dx.doi.org/10.5633/amm.2016.0310.

Dumolt, J. H., Radhakrishnan, S. K., Moghadasian, M. H., Le, K., Patel, M. S., Browne, R. W., \& Rideout, T. C. (2018). Maternal hypercholesterolemia enhances oxysterol concentration in mothers and newly weaned offspring but is attenuated by maternal phytosterol supplementation. The Journal of Nutritional Biochemistry, 52, 10-17. http://dx.doi.org/10.1016/j.jnutbio.2017.09.013. PMid:29107136.

Ellegård, L. H., Andersson, S. W., Normén, A. L., \& Andersson, H. A. (2007). Dietary plant sterols and cholesterol metabolism. Nutrition Reviews, 65(1), 39-45. http://dx.doi.org/10.1111/j.1753-4887.2007. tb00266.x. PMid:17310858.

El-Mosallamy, A. E., Sleem, A. A., Abdel-Salam, O. M., Shaffie, N., \& Kenawy, S. A. (2012). Antihypertensive and cardioprotective effects of pumpkin seed oil. Journal of Medicinal Food, 15(2), 180-189. http:// dx.doi.org/10.1089/jmf.2010.0299. PMid:22082068.

Fruhwirth, G. O., Wenzl, T., El-Toukhy, R., Wagner, F. S., \& Hermetter, A. (2003). Fluorescence screening of antioxidant capacity in pumpkin seed oils and other natural oils. European Journal of Lipid Science and Technology, 105(6), 266-274. http://dx.doi.org/10.1002/ejlt.200390055.

Gardner, C. D., Fortmann, S. P., \& Krauss, R. M. (1996). Association of small low-density lipoprotein particles with the incidence of coronary artery disease in men and women. Journal of the American Medical Association, 276(11), 875-881. http://dx.doi.org/10.1001/ jama.1996.03540110029028. PMid:8782636.

Gossell-Williams, M., Hyde, C., Hunter, T., Simms-Stewart, D., Fletcher, H., McGrowder, D., \& Walters, C. (2011). Improvement in HDL cholesterol in postmenopausal women supplemented with pumpkin seed oil: pilot study. Climacteric, 14(5), 558-564. http://dx.doi.org/ 10.3109/13697137.2011.563882. PMid:21545273.

Gylling, H., Hallikainen, M., Nissinen, M. J., \& Miettinen, T. A. (2010). The effect of a very high daily plant stanol ester intake on serum lipids, carotenoids, and fat-soluble vitamins. Clinical Nutrition, 29(1), 112118. http://dx.doi.org/10.1016/j.clnu.2009.08.005. PMid:19709787.

Hilton Chaves, M., Daniel Pella, M., Singh, R. B., Banshi Saboo, M., Krasimira Hristova, M., Nagib-Elkilany, G. E., et al.(2016). The challenges of prevention of cardiovascular diseases: a scientific statement of the International College of Cardiology. World Heart Journal, 8(4), 281.

Kampuse, S., Ozola, L., Straumite, E., \& Galoburda, R. (2015). Quality parameters of wheat bread enriched with pumpkin (Cucurbita moschata) by-products. Acta Universitatis Cibiniensis. Series E: Food Technology, 19(2), 3-14. http://dx.doi.org/10.1515/aucft-2015-0010.

Kaur, S., Panghal, A., Garg, M., Mann, S., Khatkar, S. K., Sharma, P., \& Chhikara, N. (2019). Functional and nutraceutical properties of pumpkin: a review. Nutrition \& Food Science, 50(2), 384-401. http:// dx.doi.org/10.1108/NFS-05-2019-0143.

Kreijkamp-Kaspers, S., Kok, L., Bots, M. L., Grobbee, D. E., \& van der Schouw, Y. T. (2004). Dietary phytoestrogens and vascular function in postmenopausal women: a cross-sectional study. Journal of Hypertension, 22(7), 1381-1388. http://dx.doi.org/10.1097/01. hjh.0000125435.28861.d2. PMid:15201555.

Kris-Etherton, P. M., Pearson, T. A., Wan, Y., Hargrove, R. L., Moriarty, K., Fishell, V., \& Etherton, T. D. (1999). High-monounsaturated fatty acid diets lower both plasma cholesterol and triacylglycerol concentrations. The American Journal of Clinical Nutrition, 70(6), 1009-1015. http://dx.doi.org/10.1093/ajcn/70.6.1009. PMid:10584045.

Kronenberg, F., \& Fugh-Berman, A. (2002). Complementary and alternative medicine for menopausal symptoms: a review of randomized, controlled trials. Annals of Internal Medicine, 137(10), 805-813. http://dx.doi.org/10.7326/0003-4819-137-10-20021119000009. PMid:12435217.

Lestari, B., \& Meiyanto, E. (2018). A review: the emerging nutraceutical potential of pumpkin seeds. Indonesian Journal of Cancer Chemoprevention, 9(2), 92-101. http://dx.doi.org/10.14499/ indonesianjcanchemoprev9iss2pp92-101.

Liu, R. H. (2004). Potential synergy of phytochemicals in cancer prevention: mechanism of action. The Journal of Nutrition, 134(12), 3479S-3485S.

Lyttle, K. A., Gossell-Williams, M. D., Clarke, T., Gardner, M., \& Simon, O. (2008). Influence of pumpkin seed oil supplementation on cardiovascular and histological outcomes in female non-ovariectomized and ovariectomized rats. The FASEB Journal, 22, 719-731.

Makni, M., Fetoui, H., Gargouri, N., Garoui, E. M., Jaber, H., Makni, J., Boudawara, T., \& Zeghal, N. (2008). Hypolipidemic and hepatoprotective effects of flax and pumpkin seed mixture rich in $\omega-3$ and $\omega-6$ fatty acids in hypercholesterolemic rats. Food and Chemical Toxicology, 46(12), 3714-3720. http://dx.doi.org/10.1016/j. fct.2008.09.057. PMid:18938206.

Mancia, G., Fagard, R., Narkiewicz, K., Redon, J., Zanchetti, A., Böhm, M., Christiaens, T., Cifkova, R., De Backer, G., Dominiczak, A., Galderisi, M., Grobbee, D. E., Jaarsma, T., Kirchhof, P., Kjeldsen, S. E., Laurent, S., Manolis, A. J., Nilsson, P. M., Ruilope, L. M., Schmieder, R. E., Sirnes, P. A., Sleight, P., Viigimaa, M., Waeber, B., \& Zannad, F. (2013). 2013 ESH/ESC guidelines for the management of arterial hypertension: the Task Force for the Management of Arterial Hypertension of the European Society of Hypertension (ESH) and of the European Society of Cardiology (ESC). Blood Pressure, 22(4), 193-278. http://dx.doi.org/10.3109/08037051.201 3.812549. PMid:23777479.

Miller, M., Stone, N. J., Ballantyne, C., Bittner, V., Criqui, M. H., Ginsberg, H. N., Goldberg, A. C., Howard, W. J., Jacobson, M. S., Kris-Etherton, P. M., Lennie, T. A., Levi, M., Mazzone, T., \& Pennathur, S. (2011). Triglycerides and cardiovascular disease: a scientific statement from the American Heart Association. Circulation, 123(20), 2292-2333. http://dx.doi.org/10.1161/CIR.0b013e3182160726. PMid:21502576.

Miranda, C. T. O. F., Duarte, V. H. R., Cruz, M. S. M., Duarte, M. K. R. N., de Araújo, J. N. G., Dos Santos, A. M. Q. S., de Oliveira, J. 
M., Paiva, M. S. M. O., Rezende, A. A., Hirata, M. H., Hirata, R. D. C., Ribeiro, K. D. D. S., Luchessi, A. D., \& Silbiger, V. N. (2018). Association of serum alpha-tocopherol and retinol with the extent of coronary lesions in coronary artery disease. Journal of Nutrition and Metabolism, 2018, 2018. PMid:30647971.

Montesano, D., Blasi, F., Simonetti, M., Santini, A., \& Cossignani, L. (2018). Chemical and nutritional characterization of seed oil from Cucurbita maxima L.(var. Berrettina) pumpkin. Foods, 7(3), 30. http://dx.doi.org/10.3390/foods7030030. PMid:29494522.

Nakić, S. N., Rade, D., Škevin, D., Štrucelj, D., Mokrovčak, Ž., \& Bartolić, M. (2006). Chemical characteristics of oils from naked and husk seeds of Cucurbita pepo L. European Journal of Lipid Science and Technology, 108(11), 936-943. http://dx.doi.org/10.1002/ejlt.200600161.

Nissinen, M., Gylling, H., Vuoristo, M., \& Miettinen, T. A. (2002). Micellar distribution of cholesterol and phytosterols after duodenal plant stanol ester infusion. American Journal of Physiology. Gastrointestinal and Liver Physiology, 282(6), G1009-G1015. http://dx.doi.org/10.1152/ ajpgi.00446.2001. PMid:12016126.

Patel, S. (2013). Pumpkin (Cucurbita sp.) seeds as nutraceutic: a review on status quo and scopes. Mediterranean Journal of Nutrition and Metabolism, 6(3), 183-189. http://dx.doi.org/10.3233/s12349-0130131-5.

Phillips, K. M., Ruggio, D. M., \& Ashraf-Khorassani, M. (2005). Phytosterol composition of nuts and seeds commonly consumed in the United States. Journal of Agricultural and Food Chemistry, 53(24), 9436-9445. http://dx.doi.org/10.1021/jf051505h. PMid:16302759.

Rabrenović, B. B., Dimić, E. B., Novaković, M. M., Tešević, V. V., \& Basić, Z. N. (2014). The most important bioactive components of cold pressed oil from different pumpkin (Cucurbita pepo L.) seeds. Lebensmittel-Wissenschaft + Technologie, 55(2), 521-527. http:// dx.doi.org/10.1016/j.lwt.2013.10.019.

Rafieian-Kopaei, M., Setorki, M., Doudi, M., Baradaran, A., \& Nasri, H. (2014). Atherosclerosis: process, indicators, risk factors and new hopes. International Journal of Preventive Medicine, 5(8), 927-946. PMid:25489440.

Randolph, G. J., \& Miller, N. E. (2014). Lymphatic transport of highdensity lipoproteins and chylomicrons. The Journal of Clinical Investigation, 124(3), 929-935. http://dx.doi.org/10.1172/JCI71610. PMid:24590278.

Ras, R. T., Geleijnse, J. M., \& Trautwein, E. A. (2014). LDL-cholesterollowering effect of plant sterols and stanols across different dose ranges: a meta-analysis of randomised controlled studies. British Journal of Nutrition, 112(2), 214-219. http://dx.doi.org/10.1017/ S0007114514000750. PMid:24780090.

Rezig, L., Chouaibi, M., Msaada, K., \& Hamdi, S. (2012). Chemical composition and profile characterisation of pumpkin (Cucurbita maxima) seed oil. Industrial Crops and Products, 37(1), 82-87. http:// dx.doi.org/10.1016/j.indcrop.2011.12.004.

Richter, D., Abarzua, S., Chrobak, M., Vrekoussis, T., Weissenbacher, T., Kuhn, C., Schulze, S., Kupka, M. S., Friese, K., Briese, V., Piechulla, B., Makrigiannakis, A., Jeschke, U., \& Dian, D. (2013). Effects of phytoestrogen extracts isolated from pumpkin seeds on estradiol production and ER/PR expression in breast cancer and trophoblast tumor cells. Nutrition and Cancer, 65(5), 739-745.

Ryan, E., Galvin, K., O’Connor, T. P., Maguire, A. R., \& O’Brien, N. M. (2007). Phytosterol, squalene, tocopherol content and fatty acid profile of selected seeds, grains, and legumes. Plant Foods for Human Nutrition, 62(3), 85-91. http://dx.doi.org/10.1007/s11130007-0046-8. PMid:17594521.

Schettler, V., Neumann, C., Peter, C., Zimmermann, T., Julius, U., Roeseler, E., Heigl, F., Grützmacher, P., Blume, H., \& Vogt, A. (2017). The german lipoprotein apheresis registry (GLAR)-almost 5 years on. Clinical Research in Cardiology Supplements, 12(1, Suppl. 1), 4449. http://dx.doi.org/10.1007/s11789-017-0089-9. PMid:28233268.

Sharrett, A. R., Ballantyne, C., Coady, S., Heiss, G., Sorlie, P., Catellier, D., \& Patsch, W. (2001). Coronary heart disease prediction from lipoprotein cholesterol levels, triglycerides, lipoprotein (a), apolipoproteins AI and $\mathrm{B}$, and HDL density subfractions: the Atherosclerosis Risk in Communities (ARIC) Study. Circulation, 104(10), 1108-1113. http:// dx.doi.org/10.1161/hc3501.095214. PMid:11535564.

Stevenson, D. G., Eller, F. J., Wang, L., Jane, J.-L., Wang, T., \& Inglett, G. E. (2007). Oil and tocopherol content and composition of pumpkin seed oil in 12 cultivars. Journal of Agricultural and Food Chemistry, 55(10), 4005-4013.

Stone, N. J., Robinson, J. G., Lichtenstein, A. H., Goff, D. C. Jr., Lloyd-Jones, D. M., Smith, S. C. Jr., Blum, C., \& Schwartz, J. S. (2014). Treatment of blood cholesterol to reduce atherosclerotic cardiovascular disease risk in adults: synopsis of the 2013 American College of Cardiology/ American Heart Association cholesterol guideline. Annals of Internal Medicine, 160(5), 339-343. http://dx.doi.org/10.7326/M14-0126. PMid:24474185.

Syed, Q. A., Akram, M., \& Shukat, R. (2019). Nutritional and therapeutic importance of the pumpkin seeds. Seed, 21(2), 15798-15803. http:// dx.doi.org/10.26717/BJSTR.2019.21.003586.

Torella, M., Schettino, M. T., De Franciscis, P., Colacurci, N., Salvatore, S., \& Serati, M. (2013). Intravesical therapy in recurrent cystitis: a multi-center experience. Journal of Infection and Chemotherapy, 19(5), 920-925. http://dx.doi.org/10.1007/s10156-013-0609-6. PMid:23649671.

Trialists, C. T. (2010). Efficacy and safety of more intensive lowering of LDL cholesterol: a meta-analysis of data from 170000 participants in 26 randomised trials. Lancet, 376(9753), 1670-1681. http://dx.doi. org/10.1016/S0140-6736(10)61350-5. PMid:21067804.

Usui, T. (2006). Pharmaceutical prospects of phytoestrogens. Endocrine Journal, 53(1), 7-20. http://dx.doi.org/10.1507/endocrj.53.7. PMid:16543667.

Wong, A., Viola, D., Bergen, D., Caulfield, E., Mehrabani, J., \& Figueroa, A. (2019). The effects of pumpkin seed oil supplementation on arterial hemodynamics, stiffness and cardiac autonomic function in postmenopausal women. Complementary Therapies in Clinical Practice, 37, 23-26. http://dx.doi.org/10.1016/j.ctcp.2019.08.003. PMid:31445363. 